\title{
APPLICATION OF THIN FILMS TO THE PRODUCTION OF USEFUL ELECTRIC CIRCUITS
}

\begin{abstract}
$\mathrm{T}$ HE eleventh meeting of the Dielectrics Evaporation Group was held at the Institute of Physics and the Physical Society during October 20-21. The following papers were read: "Ion Beam Deposition", by B. A. Probyn; "Thermally-grown, Pyrolytic and Sputtered Silicon Oxides", by M. J. F. Gaze and A. M. Gundlach; "The Use of Alloy Systems in the Epitaxial Growth of Silicon", by Dr. S. Nielson; "Progress in Reactive Sputtering of Oxide Films", by E. Hollands; "Effects of Film Composition on the Temperature Coefficient of NickelChromium Resistive Films", by B. Hendry; "Factors Affecting Properties and Performance of Thin-film Microcircuits", by J. L. Parmee; "Techniques for Obtaining Films of Uniform Thickness", by B. Wood; "The Role of the Active Device in Thin-film Circuits", by D. Salisbury; "A Bakable Multiple-mask Changer", by Dr. P. R. Stuart; "Some Notes on the Recent American Vacuum Society Congress", by C. Stoddart.

The tone of this meeting inclined rather more to the technological aspects of thin films than the previous ones. However, it is sometimes salutary for the worker in pure research to pay heed to the more practical application of his work. The theme was in fact the application of thin films to the production of useful electronic circuits. One fact which emerged very clearly was the need for thin-film active devices the preparation of which should be compatible with the passive circuit elements commercially available. It is somewhat depressing to note that only a small amount of fundamental research has been carried out in Britain and elsewhere on compatible thin-film active devices. It was pointed out by Mr. Parmee that the only solution to this problem at present, and for some time to come, must be to attach a semiconductor device to a thin-film passive circuit. Such devices are now available as thin flakes which do not need separate leads. He also showed, using compound methods of construction (evaporated conductors, reactively sputtered silica dielectrics and separately attached active devices), that reliable miniature assemblies can be constructed on a commercial basis.
\end{abstract}

An alternative approach to the device problem which has received widespread and influential support is the epitaxial deposition of silicon on some suitable substrate. It was made clear by Dr. Nielson that this process has by no means been perfected. Many practical difficulties arise even on the fundamental problem of producing continuous monocrystalline films. It seems untikely that processes of this type can succeed at temperatures sufficiently low to avoid damage to more normal passive components.

The problem of the thin-film active device does not arise in the so-called 'solid circuit'. In this the problem is the fabrication of integral passive circuit elements. Mr. Gaze compared silica films prepared by various methods in this connexion. He has been successful in forming capacitor films by thermal oxidation and pyrolytic deposition. This success may have influenced his decision not to persist in experiments on reactive sputtering for which Mr. Parmee had repcrted such excellent results.

The process of reactive sputtering is, due to its com. plexity, scarcely understood theoretically, and it is hoped that more fundamental research in this field may throw some light on the mechanism of deposition. In the practical field Mr. Hollands reported results on the sputtering of mixed titanates and of zirconia. $\mathrm{He}$ has confirmed that with mixed titanates, while high breakdown strengths may be obtained, they are associated with permittivities far lower than are to be expected from the bulk material. This phenomenon has been observed in other investigations of such materials. It is interesting to speculate whether or not in practice such a correlation will always be found. In the case of zirconia it was shown that adequate protection from moisture might cause a four-fold increase in dielectric strength.

Much interest is still shown in work on the preparation of nickel chromium alloy resistive films, and greater understanding of their properties is now emerging as a result of the combination of electrical measurements with electron microscope examination.

Evaporation is still the customary method of deposition. Mr. Wood described a method of producing uniform deposits over a large area using a line scurce and baffle plates. He used an optical transmission method for assess. ing uniformity of deposit as well as an optical analogue to determine the optimum geometry of the system.

Mr. Hendry related the changes in electrical properties for nickel chromium films of varying composition and different thicknesses to the structures shown by electron microscopy. He invoked the present theories of conduction in continuous and aggregated films appropriate to the different cases.

The approach of the vacuum engineer characterized the description of the bakable multiple-mask changer designed and made at the National Physical Laboratory for the preparation of cryotron arrays. This is suitable for operation in vacuum equipment at pressures down to $10^{-8} \mathrm{~mm}$ mercury, and can hold up to 24 masks.

The meeting was concluded with an account of some of the more interesting papers at the recent American Vacuum Society Symposium. It is not clear when these will be published.

It is hoped that the next meeting of the Dielectries Evaporation Group will be held some time before Easter 1965.
J. R. BALMER

\section{MAPS OF THE PERSEUS REGION AT 600 AND I,415 MEGACYCLES PER SEC}

\author{
By R. S. DIXON, S. Y. MENG and Prof. J. D. KRAUS \\ Radio Observatory, Ohio State University, Columbus, Ohio
}

$\mathrm{M}$ APS of the Andromeda Nebula ( $M 31$ ) region made at 600 and $1,415 \mathrm{Mc} / \mathrm{s}$ with the Ohio State University 260 - $\mathrm{ft}$. radio telescope have recently been published ${ }^{1}$. The maps covered 285 square degrees of sky between right ascensions of $23 \mathrm{~h} 40 \mathrm{~m}$ to $02 \mathrm{~h} 10 \mathrm{~m}$ and declinations of $36^{\circ}$ to $46^{\circ}$ (N.). Since the telescope is of the meridian transit type and runs continuously, radiometric data were obtained during the same programme not only for the 